\title{
Integrated Methodology for the Environmental Risk Assessment of an Abandoned Uranium Mining Site
}

\author{
Maria de Lurdes Dinis, António Fiúza \\ Geo-Environment and Resources Research Center (CIGAR), Mining Department, \\ Engineering Faculty, University of Porto, Rua Dr. Roberto Frias, 4200-465, Porto, \\ Portugal, mldinis@fe.up.pt; afiuza@fe.up.pt.
}

\begin{abstract}
We developed an integrated approach to evaluate quantitatively the fundamental data required to perform a risk assessment induced by the existence of uranium mine tailings disposals or any other form of low activity waste storage. From the characteristics of the radioactive sources the different types of possible releases are evaluated using phenomenological models. The concentrations in the main environmental compartments are deduced. To this data we apply models of environmental transport, dispersion and fate within each environmental compartment, as well as models of inter-compartment transfer. The activity is then predicted at predefined exposition locations, in each environment compartment. Models of transfer to the food chain were also developed allowing to estimate concentration of different radioisotopes in all the media. This data, complemented with an exposure scenario, allows a quantitative environmental risk assessment.
\end{abstract}

\section{INTRODUCTION}

The large volumes of ore manipulated in the extraction and processing operations of radioactive ores produced huge rates of useless solid wastes which were disposed, in the past, in open air areas. These waste storages generate liquids and/or gaseous releases. Wind, rainfall and biological processes tend to provoke the dispersion of the released compounds in the environment contributing to the transport, transfer and fate processes through the atmosphere, superficial aquatic systems or subsoil, leading to the contamination of new environmental sub- 
compartments. Such dispersion is of particular concern for the radioactive wastes due to the long decay periods resulting in long-term exposures.

The exposure to these materials may follow from inhalation of contaminated air, or ingestion of contaminated water or, less directly, through ingestion of contaminated foodstuffs. Although less direct this pathway may be quite significant as a result of biological magnification into the foodstuffs. External exposure to gamma radiation is also possible.

When modeling contaminant release and transport mechanisms for each environmental compartment generally the major output chosen is the contaminant concentration in each exposition point selected (for instance, breathing air at a certain height, superficial soil and water from wells). This will allow the assessment of doses, if an additional exposure scenery is considered.

We intended to apply mathematical models with phenomenological basis to the release, the dispersion and the intercompartimental transfer of low level radioactive substances. Multicompartment models were developed and adapted with the purpose to predict the activity concentration in predefined exposure points located in each one of the compartments; our research works focused essentially in the development of models concerning the release mechanisms, the radionuclides transport, its intercompartimental transfer and fate, consolidating the scientific base for estimating exposure assessments of selected components from the local ecosystem.

The models developed in this study were, after calibration, validated using data from the surrounding areas of the former Urgeiriça uranium mine site.

\section{Methods and Results}

A systematic analysis was performed in order to consider the integrated approach of the following points: i) sources; ii) release mechanisms; iii) transport mechanisms or dispersive vectors (air and water); iv) transfer mechanisms between the environmental compartments; v) estimate of concentrations in each environmental compartment using dispersion models with spatial variation; vi) definition of the privileged exposure points and vii) identification of exposed receptors.

The important routes of contamination have been identified as a basis for developing the appropriate models. The radionuclides of major concern were also identified in each one of the compartments, based on their chemical, physical and radiological properties.

It was also incorporated a radionuclide transfer model through the food chain, including also, in a more complete version of this conceptual model, the radionuclides distribution within an organism for a relevant trophic level (pasture animals) adapted from the biokinetic models present in the specialized literature.

It was also necessary to use direct extensive measurements from a contaminated site in order to calibrate the models and for its subsequent validation. The mathematical models were coded into simulation programmes developed in Matlab. 
The values for the parameters existing in the models were obtained from different sources: some parameters were taken from measurements at the Urgeiriça uranium tailings piles; others were obtained from published data referring to this site. The remaining unknown parameters were obtained from available measurements referring to other sites or from literature references, when on-site data was not available.

In the selected methodology the following main components were considered: a source term (radionuclide concentration distribution in the wastes); a multi-layer cover for the wastes (radon flux attenuation and concentrations at release available for dispersion); atmospheric pathway (radon release and dispersion by the wind); groundwater pathway (release and transport in underground waters); surface water transport (discharge and transport into superficial waters), incorporation into the flora and subsequent transfer into the food-chain. For each compartment a potential receptor or an exposition point were defined. The concentration within each compartment can then be easily transcribed to doses values based on a simplified exposure pathway and a pre-defined critical group.

\section{Source}

The usage of the models requires a previous knowledge of the main characteristics of the source: type of waste, geometry of the disposal and average chemical grades. The primary releases from the source may be alternatively provided by the user, estimated by a mathematical model or back-calculated from measured concentrations at the receptor location.

In a undisturbed uranium ore deposit secular equilibrium occurs between the ${ }^{238} \mathrm{U}$ and its decay products and between ${ }^{235} \mathrm{U}$ and its decay products. This means that as the parent nuclide has a very long half-life in relation to its radioactive daughters its concentration remains constant in time and that the activity of the daughters will be also time constant, proportional to that of the parent. This equilibrium may be disturbed by the hydrometallurgical treatment of uranium ore as a consequence of different radionuclides solubility.

Only certain nuclides are extracted by the leaching process which means that all other members of the uranium decay chain remain in the tailings at their original activities. For instance, in the ${ }^{238} U$ chain, only ${ }^{238} U$ and ${ }^{234} U$ are easily soluble; after half a year, the activities of the nuclides ${ }^{234} \mathrm{Th}$ and ${ }^{234} \mathrm{~Pa}$ have decayed to the level of the ${ }^{238} \mathrm{U}$. The activities remain at this level for tens of thousands of years (due to the 80000 year half-life of ${ }^{230} \mathrm{Th}$ ) and for an average $1 \mathrm{~kg} /$ ton ore about $71 \%$ of the radioactivity originally present in the ore remains in the tailings due to ${ }^{230} \mathrm{Th}$ and its radioactive descendents.

The estimative of the radionuclides content in the tailings was done assuming initial equilibrium before leaching in the two uranium series ${ }^{238} \mathrm{U}$ and ${ }^{235} \mathrm{U}$. The soluble isotopes were extracted with the average leaching recovery and the insoluble isotopes remained in the tailings. We admitted, based on the historical concentration ore from the region, that the major part of the tailings resulted from an ore 
with the average grade of $1 \mathrm{~kg} \mathrm{U}_{3} \mathrm{O}_{8} /$ ton being leached with a $90 \%$ recovery and a small part resulted from an ore with an average grade of $0,2 \mathrm{~kg} /$ ton which was not submitted to leaching.

Using equations based in these assumptions that include as parameters the isotopes half-lives, and as input the uranium chemical grade, it is possible to quantify the activity that will be generated by the different members of the decay chain. As result one obtains the activity concentration for each radionuclide present in the solid wastes of the uranium tailings or waste piles (Table 1).

Table 1. Activity distribution by the radionuclides presents in the solid wastes considering the treatment of a uranium ore with the average grade of $1 \mathrm{~kg} /$ ton being leached at $90 \%$.

\begin{tabular}{llllll}
\hline $\begin{array}{l}\text { Nuclide } \\
{ }^{238} \mathrm{U}\end{array}$ & $\begin{array}{l}\lambda \\
\left(\mathrm{s}^{-1}\right)\end{array}$ & $\begin{array}{l}\text { Activity } \\
(\mathrm{Bq} / \mathrm{kg})\end{array}$ & $\begin{array}{l}\text { Activity } \\
(\mathrm{Bq} / \mathrm{kg}) \mathrm{R}=90 \%\end{array}$ & $\begin{array}{l}\text { Mass at } \\
\text { Equilibrium }(\mathrm{g} / \mathrm{t})\end{array}$ & $\begin{array}{l}\text { Activity } \\
(\mathrm{Bq})\end{array}$ \\
${ }^{234} \mathrm{Th}$ & $3,33 \times 10^{-7}$ & 10375 & 1037,5 & 84,19 & 87,35 \\
${ }^{234} \mathrm{~Pa}$ & $1,01 \times 10^{-2}$ & 10375 & 1037,5 & $1,21 \times 10^{-9}$ & $1,26 \times 10^{-9}$ \\
${ }^{234} \mathrm{U}$ & $8,17 \times 10^{-14}$ & 10375 & 1037,5 & $3,98 \times 10^{-14}$ & $4,13 \times 10^{-14}$ \\
${ }^{230} \mathrm{Th}$ & $2,65 \times 10^{-13}$ & 10375 & 10375 & $4,94 \times 10^{-3}$ & $5,12 \times 10^{-3}$ \\
${ }^{226} \mathrm{Ra}$ & $1,36 \times 10^{-11}$ & 10375 & 10375 & $1,50 \times 10^{-2}$ & $1,55 \times 10^{-1}$ \\
${ }^{222} \mathrm{Rn}$ & $2,10 \times 10^{-6}$ & 10375 & 10375 & $2,87 \times 10^{-4}$ & $2,98 \times 10^{-3}$ \\
${ }^{21} \mathrm{Po}$ & $3,79 \times 10^{-3}$ & 10375 & 10375 & $1,82 \times 10^{-9}$ & $1,89 \times 10^{-8}$ \\
${ }^{214} \mathrm{~Pb}$ & $4,31 \times 10^{-4}$ & 10375 & 10375 & $9,92 \times 10^{-13}$ & $1,03 \times 10^{-11}$ \\
${ }^{214} \mathrm{Bi}$ & $5,86 \times 10^{-4}$ & 10375 & 10375 & $8,55 \times 10^{-12}$ & $8,87 \times 10^{-11}$ \\
${ }^{210} \mathrm{Tl}$ & $8,75 \times 10^{-3}$ & 10375 & 10375 & $6,29 \times 10^{-12}$ & $6,52 \times 10^{-11}$ \\
${ }^{214} \mathrm{Po}$ & $1,46 \times 10^{-4}$ & 10375 & 10375 & $4,13 \times 10^{-13}$ & $4,29 \times 10^{-12}$ \\
${ }^{210} \mathrm{~Pb}$ & $9,98 \times 10^{-10}$ & 10375 & 10375 & $2,52 \times 10^{-11}$ & $2,61 \times 10^{-10}$ \\
${ }^{210} \mathrm{Bi}$ & $1,60 \times 10^{-6}$ & 10375 & 10375 & $3,62 \times 10^{-6}$ & $3,76 \times 10^{-5}$ \\
${ }^{210} \mathrm{Po}$ & $5,73 \times 10^{-8}$ & 10375 & 10375 & $2,25 \times 10^{-8}$ & $2,34 \times 10^{-8}$ \\
\hline
\end{tabular}

\section{Multi-layer cover design}

For the case study considered, the former Urgeiriça uranium tailing disposal, the area and the average thickness of the deposit were estimated as 12 hectares and 14 $\mathrm{m}$, respectively. The tailings are characterized by an average radium content of 12 $900 \mathrm{~Bq} / \mathrm{kg}$, although they also contain much higher values in some spots (50 $\mathrm{kBq} / \mathrm{kg}$ ). The natural radioactive background in this region is $30 \mathrm{~Bq} / \mathrm{kg}$.

The radioactive decay of ${ }^{226} \mathrm{Ra}$ produces gaseous ${ }^{222} \mathrm{Rn}$ which decays into a series of short half-life products that are hazardous if inhaled. Tailings also emit gamma radiation which can increase the incidence of cancer and genetic risks.

A cover design and placement will give long term stability and control to acceptable levels of radon emission and gamma radiation, preventing also erosion and water infiltration into the tailings; generally this consists in enclosing the tailings with compacted clay or native soil to prevent the radon release and then covering this layer with rocks and vegetation ${ }^{1}$.

${ }^{1}$ A special multi-layer cover was already built. 
Radon migration to the surface is a complex process controlled mainly by porosity and moisture of the crossed media; coverers are efficient in attenuating the radon flux, as the duration of travelling for radon becomes longer and more radon will decay to non-gaseous nuclides, which are trapped by the cover system. Thereby, the efficiency depends on the capacity of the cover material for decreasing the diffusivity of radon in the media.

The basic equations of diffusion across a porous medium were used for estimating the theoretical values of the ${ }^{222} \mathrm{Rn}$ flux from the ${ }^{226} \mathrm{Ra}$ content in the waste material. The algorithm developed incorporates the radon attenuation originated by an arbitrary cover system placed over the radioactive waste disposal. As an alternative, it can be estimated the thickness of the cover that allows a radon flux inferior to the acceptable one.

An engineered cover design of 5,15 $\mathrm{m}$ average thickness composed by sand, clay and gravel was proposed on the basis of the rehabilitation plan for the site (Pereira et al. 2004). A simulation was done with this cover design to estimate the resulting radon flux attenuation and the corresponding concentration at $1 \mathrm{~m}$ above the soil, as the measured data refers to this height.

First, it was necessary to estimate the flux and the concentration considering a non-existing cover system. The values obtained in these conditions were 7,19 Bq. $\mathrm{m}^{-2} \cdot \mathrm{s}^{-1}$ for the radon flux and $547,4 \mathrm{~Bq} / \mathrm{m}^{3}$ for the concentration (Dinis 2007). The average value measured in the Urgeiriça tailings pile for the radon concentration was $557 \mathrm{~Bq} / \mathrm{m}^{3}$. This corresponds to a dose of 5,2 $\mathrm{mSv} /$ year, resulting from the exposure to radon in outdoor air, assuming that the receptor spends $1760 \mathrm{~h}$ outdoor in a year (a $20 \%$ outdoor residence time), with an equilibrium factor between ${ }^{222} \mathrm{Rn}$ and its decay products of 0,6 and for a dose conversion factor of 9 $\mathrm{nSv} \cdot \mathrm{h}^{-1}$ per Bq.m ${ }^{-3}$ (Grasty and LaMarre 2004).

The radon flux attenuation estimated by the model for the cover design proposed was about $187 \mu \mathrm{Bq} \cdot \mathrm{m}^{-2} \cdot \mathrm{s}^{-1}$ and the resulting concentration at the average breathing height was about $0,0142 \mathrm{~Bq} / \mathrm{m}^{3}$ (Dinis 2007).

The efficiency of these materials were also tested considering that the tailings will be covered with $0,5 \mathrm{~m}$ of clay plus a layer of overburden to achieve a surface flux inferior to the permissible one, which was considered to be $0,74 \mathrm{~Bq} \cdot \mathrm{m}^{-2} \cdot \mathrm{s}^{-1}$. The radon flux attenuation through the clay component cover is $2,63 \mathrm{~Bq} \cdot \mathrm{m}^{-2} \cdot \mathrm{s}^{-1}$ with a concentration of $200,23 \mathrm{~Bq} / \mathrm{m}^{3}$. The value obtained for the second layer is $1,52 \mathrm{~m}$ which gives a total cover thickness of $2,02 \mathrm{~m}$. The resulting concentration at the breathing height is $56,34 \mathrm{~Bq} / \mathrm{m}^{3}$ which corresponds to a dose, in the same previous conditions, of $0,53 \mathrm{mSv} /$ year. This dose is inferior to $1 \mathrm{mSv} /$ year, the limit derived from the European guidelines concerning the exposure of the general public to artificial radionuclides (Dinis 2007).

\section{Atmospheric pathway}

The air-transport is one of the principal pathways whereby radionuclides released from wastes sites may reach living organisms. Radionuclides may be discharged 
to the atmosphere through particle suspension and specially by radon emanation. Once airborne, the radionuclides will disperse downwind and deposit on ground surfaces in a pattern dependent on local meteorology, the location of the point releases, the nature of terrain downwind of the release and the physical and chemical characteristics of the emission. Radon will decay according to its own kinetic parameters.

The objective of this model is to predict the concentration of radionuclides at specific locations surrounding the source. The basic data needed in this model include the release rate of each radionuclide, physical characteristics of the source (release height, area, etc.) and meteorological data (stability class, wind speed, precipitation, etc.).

For the atmospheric pathway a two-dimensional model is used for calculating the radon flux diffusion from the tailings, followed by an estimation of the radon concentration at a defined mixing height from the soil which will be the starting point to the atmospheric dispersion, considered either simultaneously in each wind direction or only in the prevailing wind direction.

For the estimative of the radon concentrations it was used a box model concept which has implicit a mass balance formulation. The contamination source is defined by an emission area, or the sum of several areas, generating a constant emission rate, where the radon is diluted directly in the ambient air-breathing zone above the contaminated source zone. The box volume is defined by its length, width and the mixing height.

As a consequence of a steady state assumption, the concentration is constant in time and the mass flow rate entering into the box is equal to the flow rate leaving the box. Also the concentration is spatially homogeneous based on the assumption of complete mixing inside the compartmental box.

The atmospheric dispersion is modeled by a modified Gaussian plume equation, which estimates the average dispersion of contaminants released from the source; a plume dispersion model accounts for the contaminant transport from the source area at a specific wind-speed to a downwind receptor. The radon concentration dispersion is then simulated from the release point, at the mixing height, for defined distances in different wind directions, with different wind velocities, as well as in the dominant wind direction.

It was considered that the site is composed by four contaminated areas with different radium content. The global area was conceptually defined as a regular octagon as the national meteorological data corresponds to octants. Each octagon sector has a characteristic average wind speed according to its direction (N S E W NW NE SE SW).

The medium point for the global area was defined by the arithmetic average of the medium point for each singular area; the release point source is located in the centre the polygon area. The air breathing or mixing height was defined as $1,7 \mathrm{~m}$.

The ${ }^{222} \mathrm{Rn}$ concentration was calculated in each sector at this height without cover system. The average value obtained was $5,96 \mathrm{~Bq} \cdot \mathrm{m}^{-2} \cdot \mathrm{s}^{-1}$ (for a radium content in the tailings of $10375 \mathrm{~Bq} / \mathrm{kg}$ ) and the average concentration for the compartmental box was estimated in $73,2 \mathrm{~Bq} / \mathrm{m}^{3}$. The prevalent wind direction is to 
$\mathrm{NE}$ and the resulting concentration in this direction is $658 \mathrm{~Bq} / \mathrm{m}^{3}$ at the vicinity of the site (Fig. 1).

Dispersion in the dominant wind direction is the situation that better fits reality according to the comparison between the model results and the radon concentration measured in this direction.

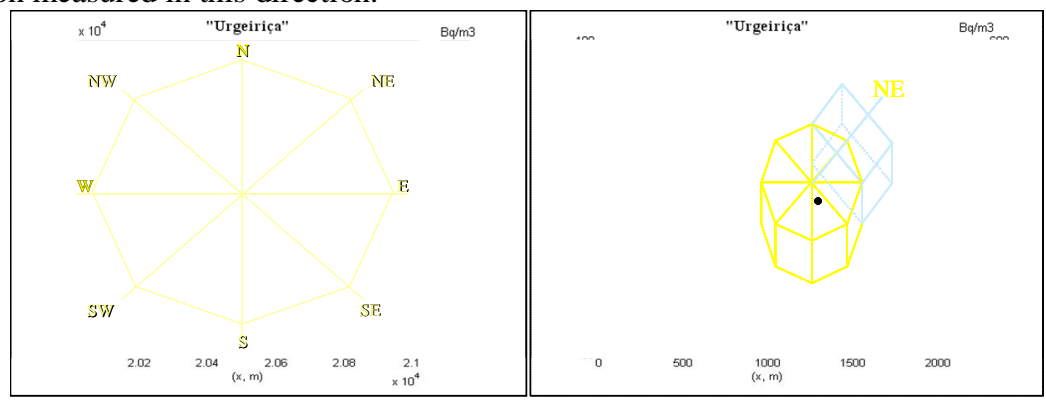

Fig.1. Radon dispersion in each wind direction and in the dominant wind direction $\left(\mathrm{Bq} / \mathrm{m}^{3}\right)$.

\section{Groundwater}

Often groundwater is an important pathway for contaminations found in the subsoil. Contaminants leached from the waste move downwards through the unsaturated zone to the saturated where they are dispersed by advection, hydrodynamic dispersion and diffusion. The contaminants may ultimately discharge to a well or to a surface stream. Humans are exposed to radioactive contaminants by using the water from well or the surface stream and eventually by eating organisms living in the stream.

For the groundwater pathway a two-direction model is proposed for simulating the contaminants release from the tailings pile and its migration process through the soil to the groundwater. The final result is the radionuclide concentration in the groundwater as function of the elapsed time, at a defined distance from the waste pile, where a well is supposed to be located.

The model calculations are broken down into three linked sub-models: i) contaminant leaching from the tailings; ii) vertical movement of the dissolved contaminant downward to the water table through the unsaturated zone and iii) migration of the contaminant in saturated groundwater to the receptor point.

A leaching model based on a sorption-desorption process is used for describing the contaminant release from tailings. The leachate concentration is determined by a partition coefficient $\left(\mathrm{K}_{\mathrm{d}}\right)$, which describes the relative extent of contaminant transfer to pore water, by soil properties, such as bulk density and moisture, and by the magnitude of the contamination described by the total amount at the source and by the thickness.

The vertical flow transporting the dissolved contaminants is considered to be one-dimensional. It is assumed that there is retardation during the vertical trans- 
port which is estimated assuming that the adsorption-desorption process can be represented by a linear isotherm.

Movement and fate of radionuclides in groundwater follow the transport components represented by the basic diffusion/dispersionï advection equation: an analytical solution was used for the one dimensional transport of a reactive substance with simultaneous retardation and radioactive decay.

The radionuclides initially considered in the simulation model were uranium, thorium, radium, polonium and lead. It was observed that ${ }^{230} \mathrm{Th}$ and ${ }^{210} \mathrm{~Pb}$ are not transported to significant distances by the groundwater. This may be explained by the particle-reactive nature of thorium and lead. For polonium the results were in accordance with the expected, based on the assumption that due to the slow rate of contamination migration only the radionuclides with relatively long half-life are of importance in the transport process.

Analytical measures of the uranium and radium activity in groundwater and superficial waters from the Urgeiriça site were used for comparison with the model results. The analytical results show somehow similar values with those obtained in the model. The medium value for total uranium in the well water was about 1,6 $\mathrm{Bq} / \mathrm{L}$ and for radium was about $0,4 \mathrm{~Bq} / \mathrm{L}$. These values are achieved in the model within the first 30 years after the aquifer contamination. These results correspond to an effective dose of $0,082 \mathrm{mSv} / \mathrm{Bq}$ for ${ }^{226} \mathrm{Ra}$ and of $0,053 \mathrm{mSv} / \mathrm{Bq}$ for ${ }^{238} \mathrm{U}$, considering an annual ingestion rate of $730 \mathrm{~L}$ and an effective dose coefficient of 2,8 x $10^{-4} \mathrm{mSv} / \mathrm{Bq}$ and $4,5 \times 10^{-5} \mathrm{mSv} / \mathrm{Bq}$ for ${ }^{226} \mathrm{Ra}$ and for ${ }^{238} \mathrm{U}$, respectively.

Considering radionuclides dispersion through groundwater system, it was observed that there are two preferential plume contamination directions, whether uranium or radium is considered. These two directions suggest that SW-NE direction is preferential to radium dispersion and that NW-SE direction is preferential to uranium dispersion (Fig. 2). This allowed us to identify two preferential contamination targets: at south to radium and at north to uranium.
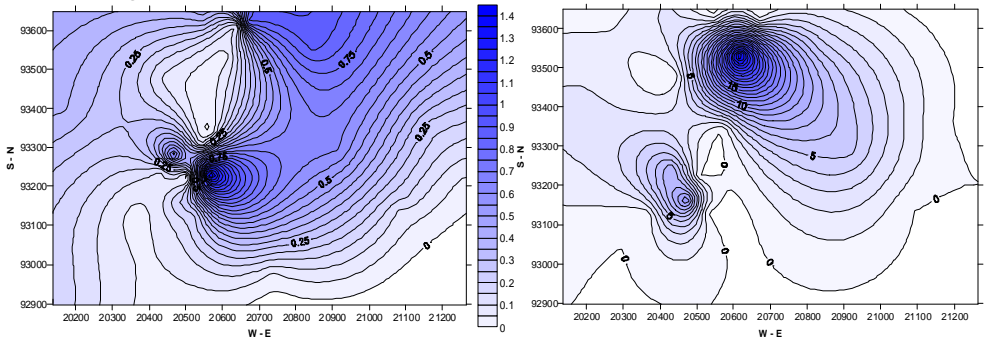

Fig.2. Radium and Uranium contamination dispersion in groundwater $(\mathrm{Bq} / \mathrm{L})$.

\section{Surface water transport}

Surface water can be an important pathway for contaminants transport from a waste disposal; the surface water bodies include lakes, streams, rivers and runoff 
processes. Contaminants present on the surface of a waste site may become suspended or dissolved in surface runoff and be transported to adjacent bodies of surface water. Exposure to humans may occur then through drinking and using contaminated surface water or by eating organisms living in these water bodies and by external irradiation from radionuclides sediments.

This model describes the radionuclides transport and transfer in superficial waters. The specific case of radionuclides discharge into stream waters was considered for applying this model to the study site.

The radionuclide transport and fate in surface waters are described by the advection-diffusion equation in a three dimension form (IAEA 2001). The generic governing equation was simplified to obtain appropriate solutions, according to the water body to consider, estimating the radionuclide concentration in steady state flow conditions at a defined distance from the discharge point, where is considered to be located the exposure point or the potential receptor.

The liquid effluents from the uranium chemical treatment at Urgeiriça site have been discharged for many years into a stream near the contaminated site, ñRibeira da Pantanhaò, which is also the main watercourse that drains the mining area. For this reason a simulation was done with the discharge into this watercourse of an effluent contaminated with a radium concentration of $271 \mathrm{~Bq} / \mathrm{m}^{3}$.

Several exposure points were considered along this watercourse strategically defined by the available experimental data. Radium concentration in superficial waters was estimated at these points to determine the relation between the diluted concentrations and the distance to the discharge local. The concentration in the river sediments was also estimated for the same exposure points.

The model results suggest a clear decrease in radium concentration downstream with the distance to the discharge point. Radium concentration in sediments follows the same variation pattern.

Comparing the model results with the measured data for radium concentration in the exposition points it was observed that the highest values both in water and sediments do not correspond to the discharge point considered but at a distance comprised between 1650 and $2750 \mathrm{~m}$ distant from the discharge point. The radium concentration continues to decrease with the distance afterwards. This suggested that probably there are other contamination sources besides the discharged effluent as the model considers the contaminated effluent as the only source of contamination.

\section{Transfer to flora}

Modeling the radionuclide transfer to vegetation has implicit several simpler processes which describe and quantify mathematically the radionuclides transfer mechanisms, such as uptake, transport, translocation and absorption by leaves. The main goal in this step was to develop a radionuclide transfer model through food chain by the ingestion of contaminated vegetation. 
Vegetation may be contaminated through direct deposition, root uptake or irrigation with contaminated water. The material resuspension from superficial soil may occur due to the wind, rain or mechanical factors, with later deposition onto vegetation surface. A model was developed to describe each one of these contamination pathways: root uptake, deposition and resuspension, either from deposition or from irrigation with contaminated water from a well.

The different contamination processes were combined in a global model to simulate the radionuclide transfer resulting from each one of the contamination processes. The final output is the total concentration in the vegetation combining the internal contamination with the external contamination.

The conceptual model is based on the assumption that each one of the transfer processes may have origin either in soil or in the air. In the first case, the processes involved are deposition (characterized by the deposition velocity), interception (described by the interception factor) and retention (described by the weathering half-life). In the second case, the radionuclide behavior in soil and its mobilization reflects the radionuclides physics and chemical properties, soil properties, the type of vegetation and local hydrology and geology characteristics.

The model was applied to ${ }^{238} \mathrm{U},{ }^{234} \mathrm{Th},{ }^{234} \mathrm{U},{ }^{230} \mathrm{Th},{ }^{226} \mathrm{Ra},{ }^{222} \mathrm{Rn},{ }^{214} \mathrm{~Pb},{ }^{210} \mathrm{~Pb}$. It was observed that deposition is the most expressive pathway. The lowest values were obtained for ${ }^{222} \mathrm{Rn}$ which may be explained by its physical state; being an inert gas it can easily disperse into the atmosphere without suffering deposition. The

${ }^{214} \mathrm{~Pb}$ is almost inexistent which may be explained by the fact that the weathering decay constant is almost equivalent to the radioactive decay constant; this means that when ${ }^{214} \mathrm{~Pb}$ decays to its daughter isotope, it is simultaneously removed.

Some authors (Madruga et al. 2000) studied ${ }^{226} \mathrm{Ra}$ uptake from Urgeiriça uranium tailings. It was observed that plant uptake for total radium concentration in the tailings follows a non-linear function form $\left(\log C_{p}=\log a+b \log C_{s}\right)$, tending however to a linear relationship at higher radium concentration in the tailings (Madruga et al. 2000). This function was used in this sub-model.

Sheppard and Sheppard (1985) proposed a dose-response curve for plant uptake of essential and non-essential elements to explain this radium absorption behavior. These authors reported that plants readily uptake elements essential for plant growth when substrate concentrations are low (deficient), whereas plant uptake of non-essential elements is generally constant at high substrate concentration. On the other hand, at high substrate concentrations, plant uptake of essential and nonessential elements can either be constant (no toxicity) or can decrease leading to toxicity or death (Martinez and Periánez 1998).

Considering this approach to ${ }^{226} \mathrm{Ra}$ absorption it appears that radium behave as an essential element at low substrate concentrations as plant uptake depends on radium concentration in the tailings.

\section{Transfer into the Food-chain}

Food chains are biosphere pathways through which humans are exposed to environmental contaminants. They represent the contaminants bioaccumulation in the 
edible portion of animals and plants that are affected by their release and dispersion from the contaminated site. Food chains consist of one or more trophic levels between the physical environment and human intake of contaminants.

Radionuclides deposition can be a significant pathway to human exposure starting by ingestion of contaminated pasture by animals and then by the ingestion of contaminated animal products (dairy or meat). Plants in general tend to accumulate radionuclides in a scale dependent on many factors and within animals and humans, certain tissues tend to accumulate selected radionuclides. The relevant incorporation of the radionuclides in the milk is usually due to the ingestion of contaminated pasture. This transfer process is often called the pasture-cow-milk exposure route.

A dynamic compartmental model was developed to describe the radionuclide behavior in the pasture-cow-milk exposure route and predict the activity concentration in each compartment following an initial radionuclide deposition.

The dynamic model is defined by a system of linear differential equations with constant coefficients based in a mass balance concept. For each compartment a transient mass balance equation defines the relations between the inner transformations and the input and output fluxes. The fluxes between the compartments are estimated with a transfer rate proportional to the amount of the radionuclides in the compartment. The concentration within each compartment is then transcribed to doses using a simplified exposure pathway and a pre-defined critical group.

The first model considered for the transfer through the food chain is relatively simple and classic and considers as initial state a contaminated pasture that is consumed by a cow producing a certain quantity of milk. A more sophisticated model is also described taking into account the spread of the radionuclide within the cow by including the sub-compartments involved: the gastrointestinal system (GIT), the plasma and the bones, in the case of radium simulation. The endpoints are radium concentrations in the soil, pasture, GIT, plasma, bone and milk.

For the exploration of the model several radionuclides were defined as relevant but only for radium and polonium was done a complete model simulation. For uranium, thorium and lead it was only applied the simple model due to either the irrelevance of the results or the lack of data to define the necessary parameters and validate the model. It wasnâ possible to obtain data referring to the study site concerning this exposure route. Data from other similar contaminated sites were used.

For radium transfer through this pathway seven sub-compartments were defined: soil, pasture, GIT, plasma, bone surface, bone volume and milk. Concerning to radium absorption, model results (Fig. 3) are coherent with data published referring to radium absorption through this pathway (Leggett and Eckerman 2003; IAEA 2004; Beresford et al. 2004). After ingestion, radium is quickly spread to organs tissues until its maximum absorption, followed by an immediate decrease in blood.

However, the sub-compartment represented by bone tissue doesnâ follow this pattern as some organs and tissues, notably bones, have the capacity to concentrate radium from blood and, although some of the radium is excreted over a long time, 
a portion will remain in the bones throughout the organismôs lifetime. This is due to the radium chemical similarity with calcium.

For ${ }^{210} \mathrm{Po}$ it was necessary to define 14 sub-compartments to account all transfers rates and 36 kinetic transfer constants. This implied to define a 14 differential equations system (Dinis and Fiúza 2007). Concerning ${ }^{210}$ Po transfer through the food-chain there are no experimental studies documenting ${ }^{210} \mathrm{Po}$ transfer from feed to animal products. The only experimental works documented refer to the direct ${ }^{210} \mathrm{Po}$ introduction into animal body or to animalôs products collection from contaminated areas. Nevertheless, simulation results for ${ }^{210} \mathrm{Po}$ (Fig. 3) fit within the range of values given in the literature although many assumptions had to be done due to the limited available data; conservative parameters had to be used in some cases (Leggett and Eckerman 2003; IAEA 2004; Beresford et al. 2004).

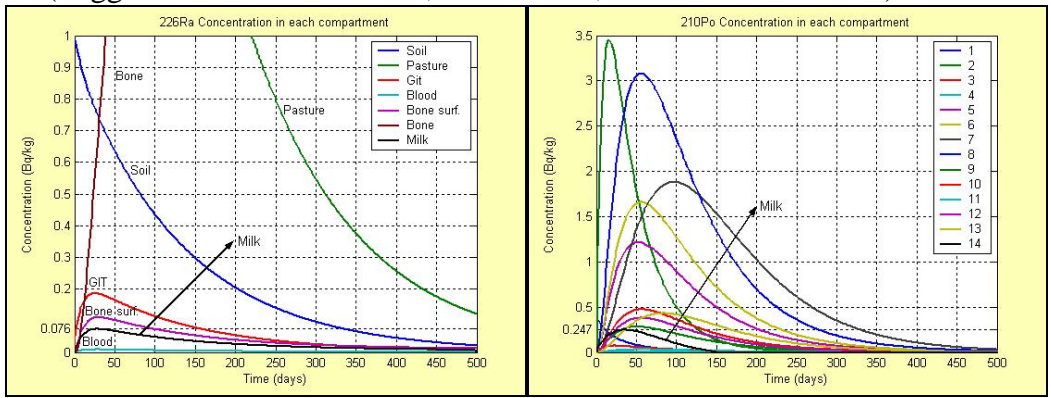

Fig.3. Radium and Polonium concentration in each compartment, complete model (Bq/kg).

\section{Discussion and Conclusions}

An integrated global model has been developed for evaluating the external exposure resulting from radionuclide dispersion having as main logical structure a global conceptual model and as secondary tools some particular and restricted quantitative sub-models of transfer and fate. The assessment requires a clear definition of the environmental path and the final fate for each toxic element retained.

For each step involved in the global conceptual model, release and transport by dispersive vectors, phase transfer resulting in retardation and attenuation and environmental exposure of biota, flora, cattle and humans, data were collected and adapted from different sources. The final result is an integrated model for assessment of external exposure originated by low activity radioactive wastes.

The mathematical realization of the sub-models is not uniform: i) some are partially formulated as a set of first order differential equations and partly analytical equations are applied; ii) some sub-models are solved by a set of analytical equations and some of these are analytical solutions of the differential equations. The underlying equations are described in detail for each sub-model in Dinis (2007). 
A sensitivity analysis was performed in order to identify the most critical sitespecific parameters in each sub-model.

The radon release and transport through the tailings depends on radon diffusion coefficient which greatly varies with material moisture and porosity. These parameters will vary over the year due to the climatic changing. It also depends on radium content in the tailings, which is highly heterogeneous at Urgeiriça tailings, and on the water retention, which is also a seasonal parameter, with spread values at the Urgeiriça site. The major complexity in radon flux estimative relies precisely on these on-site parameters variability, both in space and in time.

When modeling radon dispersion the obvious limitations are related to the reduction of the source to a point, being implicit a flat terrain (topography is not considered), wind velocity is constant with height and the dispersion is only twodirectional. Nevertheless, the errors arising from these assumptions will have a negligible effect for the exposure assessment, because the distance to the exposed receptors is large compared to the stack height, area or facility size.

For the groundwater pathway it is assumed that vertical transport occurs through a partially saturated porous media. The mathematical model that quantifies this transport has implicit the estimative of the retardation factor and flow velocity. The simplified approach used is acceptable as any error introduced at this stage would only affect the radionuclide arrival time and has little effect on concentration in well water for long-lived radionuclides. The exception is for shortlived radionuclides; however these are not a major concern in this pathway as only radionuclides with relatively long half-life are of importance in the transport process due to the slow rate of contamination migration.

Many specific soil parameters can affect the time it takes for a radionuclide to travel to groundwater. In particular, the radionuclide distribution coefficient $\left(\mathrm{K}_{\mathrm{d}}\right)$ plays an important role in determining the resulting potential exposure because it is a measure of how readily one species sorbs to a surface and sorption retards the overall movement of radionuclides. This is the most critical parameter due to its variability and due to the complexity for determining its value as it is influenced by many factors.

Transfer to flora sub-model is rather complex as it is necessary to understand and transcribe to the conceptual model the interactions between the contaminants and the soil components, vegetation, as well as the interactions between the contaminants themselves.

These processes will be described by the on-site specific parameters: interception factor, translocation factor, transfer soil-plant and $K_{d}$ values, which will depend mostly on soil properties, plant specie, local hydrology and geology and radionuclides physical and chemical properties.

The parameters independent of the radionuclide characterize environmental and ecological characteristics that vary from site to site and also with the spatial scale considered. These parameters related to vegetation, soil and fauna characteristics, can be directly obtained from on-going site investigation or estimated with simple models. However, the experimental data will always and only represent a limited set of environmental conditions. 
Some parameters are specific for each radionuclide and they are responsible for differences in distribution in the compartments, as well as for their retention and elimination from the system. For instance, the quantity absorbed by vegetation generally is estimated by a transfer factor (FT) which defines the ratio between the activity in the vegetation and the activity in the soil. This is one of the parameters presenting a vast lack of data and consequently unreliable intervals of confidence.

Studies documenting radionuclide transfer from crop to animal products are not abundant and most of them do not contain the necessary information as the radionuclide concentration in the animalôs diet. The existing studies are the result of acute controlled feeding exposure, direct radionuclide introduction into animals or sample collection from animals feeding near contaminated areas.

\section{References}

Beresford N.A., Broadley M.R., Howard B.J., Barnett C.L., White P.J. (2004), Estimating Radionuclide Transfer to Wild Species-Data Requirements and Availability for Terrestrial Ecosystems, Journal of Radiological Protection (24): A89-A103, online: stacks.iop.org/JRP/24/A89.

Dinis M.L. (2007), Phenomenological Models for the Inter-Compartmental Distribution of Radioactive Substances, Doctoral Degree in Environmental Engineering, Porto, FEUP.

Dinis M.L., Fiúza A. (2007), Models for the Transfer of Radionuclides in the Food Chain, in: International Conference on Environmental Radioactivity from Measurements and Assessments to Regulation, Book of Extended Synopses, IAEA-CN-145, pp. 322-323.

Grasty R.L., LaMarre J.R. (2004), The Annual Effective Dose From Natural Sources of Ionising Radiation in Canada, Radiation Protection Dosimetry, Vol. 108, No. 3, pp. 215-226, DOI: $10.1093 / \mathrm{rpd} / \mathrm{nch} 022$.

IAEA International Atomic Energy Agency (2001), Generic Models for Use in Assessing the Impact of Discharges of Radioactive Substances to the Environment, Safety Reports Series N. ${ }^{\circ}$ 19, IAEA: Vienna, Austria.

IAEA International Atomic Energy Agency (2004), Biomass ï 7, Testing of Environmental Transfer Models Using Data from the Remediation of a Radium Extraction Site, Report of the Remediation Assessment Working Group of Biomass, Theme 2.

Leggett R.W., Eckerman K. F. (2003), Dosimetric Significance of the ICRPô Updated Guidance an Models, 1989-2003, and Implications for U. S. Guidance, Oak Ridge National Laboratory, ORNL/TM-2003/207.

Madruga M.J., Brogueira A., Alberto G., Cardoso F. (2001), ${ }^{226}$ Ra Bioavailability to Plants at the Urgeiriça Uranium Mill Tailings Site, Journal of Environmental Radioactivity, 54, pp. 175-188.

Martinez-Agguire A., Periánez R. (1998), Soil to Plant Transfer of ${ }^{226}$ Ra in a Marsh Area: Modelling Application, Journal of Environmental Radioactivity, 39(2), 199-213.

Pereira A.J.S.C., Dias J.M.M., Neves L.J.P.F., Nero J.M.G. (2004), Modeling of the long term efficiency of a rehabilitation plan for a uranium mill tailing deposit (Urgeiriça $̈$ Central Portugal), XI International Congress of the International Radiation Protection Association.

Sheppard M., Sheppard S.C. (1985), The plant concentration ratio concept as applied to natural U. Health Phys., 48, 494500. 